\title{
Conhecimentos e práticas locais relacionados ao aratu Goniopsis cruentata (Latreille, 1803) em Barra de Sirinhaém, litoral sul de Pernambuco, Brasil
}

\author{
Daniele Claudino Maciel ${ }^{1}$ \& Ângelo Giuseppe Chaves Alves ${ }^{1,2}$ \\ ${ }^{1}$ Departamento de Biologia, Universidade Federal Rural de Pernambuco. \\ Rua Manoel de Medeiros, s/n, Dois irmãos, CEP 52171-900, Recife, PE, Brasil \\ ${ }^{2}$ Autor para correpondência: Ângelo Giuseppe Chaves Alves, \\ e-mails:agcalves@db.ufrpe.br,agcalves@yahoo.com
}

MACIEL, D. C. \& ALVES, A. G. C. Local knowledge and practices related to Goniopsis cruentata (Latreille, 1803) in a coastal village in the State of Pernambuco, Northeast Brazil. Biota Neotrop., 9(4): http://www. biotaneotropica.org.br/v9n4/en/abstract?article+bn00609042009.

\begin{abstract}
This work documents and analyses local knowledge and pratices on Goniopsis cruentata (Latreille, 1803) among traditional gatherers in Barra de Sirinhaém, a coastal village in the State of Pernambuco, Northeast Brazil. Local knowledge was registered through open and semi-structured interviews. Many aspects of behavior, taxonomy, external morphology, reproduction and feeding habits of the crustacean under study are known by the women who participated as informants. This local knowledge, which gives the informants the ability to perform their daily gathering practices, seems to be, in some cases, compatible with published scientific knowledge about the same issues.
\end{abstract}

Keywords: ethnoecology, mangroves, Brachyura.

MACIEL, D. C. \& ALVES, A. G. C. Conhecimentos e práticas locais relacionados ao aratu Goniopsis cruentata (Latreille, 1803) em Barra de Sirinhaém, litoral sul de Pernambuco. Biota Neotrop., 9(4): http:// www.biotaneotropica.org.br/v9n4/pt/abstract?article+bn00609042009.

Resumo: Este trabalho teve o objetivo de registrar e avaliar os conhecimentos e práticas locais em relação aos aratus Goniposis cruentata (Latreille, 1803) junto a um grupo de catadoras em Barra de Sirinhaém, litoral norte de Pernambuco, Nordeste do Brasil. Para obtenção dos dados referentes ao conhecimento local, utilizou-se entrevistas abertas e semi-estruturadas. Observou-se entre as pessoas entrevistadas a existência de um conjunto de conhecimentos sobre o ecossistema manguezal e sobre aspectos biológicos e ecológicos do aratu, como habitat, hábito, ecologia trófica, morfologia externa, comportamento, desenvolvimento e reprodução. Este conhecimento local, que habilita as informantes a exercerem suas práticas cotidianas, mostrou-se, em alguns casos, compatível com o conhecimento científico publicado sobre os mesmos temas.

Palavras-chave: ethnoecology, mangroves, Brachyura. 


\section{Introdução}

Os manguezais são ecossistemas de transição entre os ambientes oceânico e terrestre e abrigam comunidades vegetais típicas de ambientes alagados, resistentes à alta salinidade da água e do solo (Rebelo \& Medeiros, 1988). A fauna encontrada nos manguezais é composta por várias espécies de invertebrados e vertebrados, dentre as quais muitas possuem um valor nutritivo e econômico significante para o ser humano, a exemplo de alguns crustáceos, moluscos e peixes.

Dentre as várias razões para se estudar os manguezais destaca-se o fato de que muitas comunidades humanas têm uma dependência tradicional desses ecossistemas para sua sobrevivência (Alves \& Nishida 2002). Neste contexto, os crustáceos Brachyura representam um dos grupos de maior relevância econômica para as populações humanas que vivem nas proximidades (ou dentro) dos manguezais. Goniopsis cruentata é um desses crustáceos capturados nos manguezais, especialmente nos estuários de Pernambuco, onde se destaca por seu valor econômico, constituindo importante fonte de renda e proteína para as populações ribeirinhas (Moura \& Coelho 2004).

Conhecido popularmente como aratu, G. cruentata pertence à família Grapsidae (subfamília Grapsinae) e é encontrado ao longo da costa oeste da África, no Pacífico Americano e no Atlântico Ocidental, desde as Bermudas, Flórida, Golfo do México, Antilhas, Guianas, até o território brasileiro, do estado do Pará até as proximidades de Santa Catarina (Melo 1996). Embora se reconheça a importância socioeconômica da captura de G. cruentata no Nordeste do Brasil, pouco se conhece sobre a estrutura populacional e outros aspectos biológicos dessa espécie, principalmente no litoral Sul de Pernambuco (Santos \& Botelho 2002).

Tendo em vista a importância ecológica e econômica de G. cruentata, foi realizada uma pesquisa etnoecológica com o objetivo de registrar e avaliar os conhecimentos e práticas locais em relação aos aratus e seus habitats, estabelecendo comparações e articulações com o saber científico formal.

\section{Material e Métodos}

\section{Caracterização da área em estudo}

Barra de Sirinhaém é um distrito do município de Sirinhaém, localizado no litoral sul do estado de Pernambuco. Os manguezais de Barra de Sirinhaém, estão entre os mais expressivos desse estado. Esses ecossistemas incluem uma variada fauna e oferecem ambiente propício para a reprodução de muitas espécies. Além de serem utilizados em atividades extrativistas, fornecem condições para a realização de pesca estuarina, ostreicultura e também para a o turismo ecológico (CPRH, 2003).

A zona estuarina de Barra de Sirinhaém é composta pelos rios Arrumador, Trapiche, Aquirá e Sirinhaém. Em largas faixas marginais a estes rios e seus pequenos afluentes, espraiam-se extensas áreas de manguezal, que de norte a sul têm uma extensão aproximada de $10 \mathrm{~km}$, enquanto de leste a oeste possuem aproximadamente $5 \mathrm{~km}$ (Braga, 1986).

A flora é caracterizada principalmente pela presença de Rhizophora mangle, Laguncularia racemosa, e espécies do gênero Avicennia. Em relação à fauna observa-se a presença de moluscos típicos de regiões estuarinas, como Crassostrea rhizophorae (Guilding, 1828), "ostrade mangue"; Tagelus plebeius (Lightfoot, 1786), "unha-de-velho"; Iphigenia brasiliensis (Lamarck 1818), "taioba" e Anomalocardia brasiliana (Gmelin, 1791), "marisco-pedra”. Outro grupo faunístico que caracteriza esse ambiente estuarino é constituído pelos crustáceos (Braga, 1986). Dentre estes se destacam os de interesse comer- cial como: Ucides cordatus (Linnaeus, 1763), "caranguejo-uçá"; Cardisoma guanhumi (Latredle, 1825), "guaiamum"; Callinectes spp, "siris"; Goniopsis cruentata (Latreille, 1803), "aratu-do-mangue" e Macrobrachium acanthurus (Wiegmann, 1836), "camarão". Além dos diversos invertebrados, alguns peixes como tainha, Saúna e carapeba e algumas aves como o flexa-peixe, maçarico e socó são comumente encontrados nesse estuário (Braga, 1986).

\section{Coleta e análise de dados}

A população alvo desse estudo foi constituída por um grupo de quinze catadoras de aratu residentes em Barra de Sirinhaém. A amostra foi estabelecida utilizando-se a técnica denominada bola de neve ("snowball sampling”), na qual alguns informantes são previamente identificados e, após serem entrevistados são solicitados a indicar novos possíveis informantes para a pesquisa (Bernard 2005). A amostragem foi considerada suficiente com base no efeito de uma inclusão progressiva que permitiu aplicar o critério da exaustividade (Andrade et al. 2006).

Os trabalhos de campo iniciaram-se em outubro de 2006 e se estenderam até janeiro de 2008. Durante este período foram realizadas visitas aleatórias ao campo, sem calendário pré-definido, pois as datas das visitas foram estabelecidas a partir de diálogos com as catadoras. Estas escolhiam o dia apropriado, com base na disponibilidade das mesmas para as entrevistas e na variação das marés.

As informações sobre o conhecimento local referente aos aratus e seus habitats foram obtidas por meio de turnês guiadas (Spradley 1979) dentro dos manguezais, bem como por entrevistas nas próprias residências das catadoras. A coleta de dados foi realizada em duas etapas: na primeira etapa empregou-se a "metodologia geradora de dados" (Posey 1986, Moura \& Marques 2007). Tal metodologia consiste na aplicação de perguntas abertas, permitindo que os informantes respondam segundo sua própria lógica e conceitos. Ainda nesta etapa foram identificadas duas informantes principais ou "consultoras locais" (Moura \& Marques, 2007), escolhidas pelos autores após terem sido reconhecidas pelos seus próprios pares como detentoras de maior experiência e conhecimento sobre os temas abordados nesta pesquisa. Ambas mantinham o hábito de pescar desde a infância e tinham obtido o conhecimento da pesca junto às suas ascendentes familiares. Outras treze catadoras, que participaram com menor intensidade e frequiência em atividades de coleta de dados junto com os autores, foram consideradas como informantes secundárias.

Utilizando os termos e categorias cognitivas locais, identificados na etapa inicial e com as informantes principais já estabelecidas, iniciou-se a segunda etapa, a qual se caracterizou pela aplicação de entrevistas semi-estuturadas, tendo como tema central o conhecimento das informantes sobre os aratus e seus habitats. Em ambas as fases as informações de campo foram registradas com auxílio de um gravador e caderneta de campo. Observações diretas sobre a pesca do aratu foram feitas nos momentos em que os autores acompanharam as catadoras até o manguezal.

Tabelas de cognição comparada (Marques 1995), foram utilizadas para estabelecer comparações entre as informações provenientes do saber local (obtidas durante as entrevistas) e aquelas encontradas na literatura formal sobre os mesmos temas. Para registrar o conhecimento das catadoras sobre a morfologia externa do aratu, foi utilizado um desenho esquemático no qual as entrevistadas puderam indicar e nomear as partes externas constituintes do animal.

\section{Resultados e Discussão}

O animal coletado e conhecido pelas informantes como "aratu" é da espécie G. cruentata. O material utilizado pelas catadoras para a pesca do aratu é uma vara de bambu, uma linha de náilon, um anzol 
e uma isca, sendo esta geralmente constituída por tecidos mortos de peixes, moluscos e crustáceos. Durante a pesca, as catadoras lançam a isca (presa à extremidade da linha) para a superfície do substrato. Em seguida, o aratu utiliza o quelípodo para recolher a isca, de modo que fica preso ao anzol, e é rapidamente lançado para um saco. De acordo com as informantes, é apropriado vestir roupas que cubram a maior parte do corpo, de modo a proteger-se de picadas dos insetos e acidentes. Segundo Moura et al. (2003), a maior parte dos catadores do litoral Norte e Sul de Pernambuco captura o aratu da mesma forma, utilizando vara, linha e isca. A utilização deste método representa um importante fator na preservação do estoque desta espécie, devido à seletividade em relação aos indivíduos juvenis e menores (Moura et al. 2000). Por outro lado, Coutinho \& Moura (2008), registrou que catadores da Comunidade de São Lourenço, litoral norte de Pernambuco, utilizam também a estratégia de pesca de facheado. Esta técnica consiste na utilização, pelos catadores, de uma lamparina a querosene para facilitar a captura, durante a lua nova (Nishida 2005). Nesse caso, a luz ofusca os aratus, estes ficam imobilizados e são facilmente capturados

Durante as tentativas de captura do aratu, as raízes do mangue-vermelho, denominadas pelas catadoras de "gaiteiras", servem de apoio para essas mulheres (Figura 1). O termo "gaiteira" foi utilizado também por Braga (1986) como nome local para se referir a Rhizophora mangle, descrita pelo autor como uma espécie característica dos manguezais da região. As catadoras retiram alguns galhos do mangue e passam a percuti-los nas gaiteiras, assobiando simultaneamente, com objetivo de atrair os aratus, os quais subseqüentemente saem de suas tocas, como foi observado in situ pelos autores. Em seu estudo sobre a pesca no litoral Norte de Pernambuco Moura et al. (2003) relatou que além dos assobios, os catadores costumam bater em recipientes de plástico ou metal para atrair esses animais. Em sua obra "Zoologia dos Invertebrados", um dos principais livros-texto de zoologia em nível universitário no Brasil, Ruppert \& Barnes (1996) relatam que os órgãos sensoriais dos crustáceos incluem olhos, estatocistos, pêlos sensoriais e proprioreceptores, embora não citem textualmente o termo "audição" para descrever a percepção sensorial dos crustáceos. Entretanto, todas as catadoras entrevistadas afirmaram que esses animais "escutam" e reagem aos assobios delas.

Neste sentido, não se deve desconsiderar a possibilidade de que os aratus respondam aos estímulos sonoros produzidos pelos
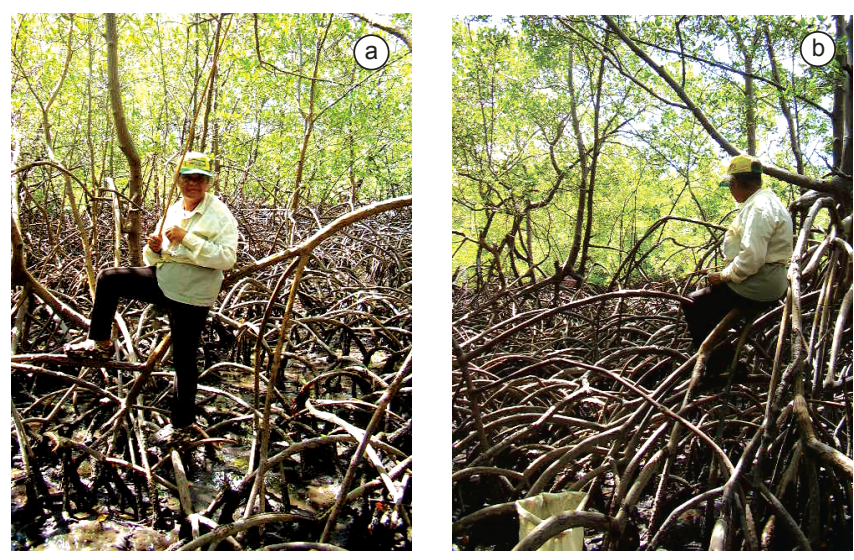

Figura 1. (a) e (b). Catadora de aratus apoiando-se nas "gaiteiras" (Rhizophora mangle) durante sua jornada de trabalho no manguezal. Foto: Raiana Lira Cabral.

Figure 1. (a) and (b). Crab gatherer leaning against branches of Rhizophora mangle during her gathering work in the mangrove. Photo by Raiana Lira Cabral. assobios emitidos pelas catadoras e pelas batidas provocadas nas gaiteiras com o auxílio dos galhos de mangue. Uma vez que não há registro disponível de resultados publicados de experimentos em que tenha sido testada a capacidade auditiva de $G$. cruentata, algumas informações sobre aspectos bio-acústicos de outros crustáceos podem ser consideradas úteis na condição de dados preliminares correlatos. Sobre este aspecto, vale ressaltar que em um experimento realizado com o Decapoda Paleamon serratus, conhecido popularmente como camarão-branco, foi observado que este representante do subfilo Crustacea é capaz de perceber freqüências sonoras em uma escala entre 100 a $3000 \mathrm{~Hz}$. Os autores do respectivo artigo (Lovell et al. 2005) expressaram-se do seguinte modo sobre o assunto: "[...] P. serratus is shown here to be sensitive to the motion of water particles displaced by low-frequency sounds ranging from $100 \mathrm{~Hz}$ up to $3000 \mathrm{~Hz}$, with a hearing (grifo nosso) acuity similar to that of a generalist fish". Ainda neste sentido, nos crustáceos da infra-ordem Brachyura, os órgãos para recepção de sons incluem os órgãos cordotonais e as junções entre os artículos das patas ambulatórias (Encyclopædia Britannica 2008). Estes órgãos cordotonais são mecanotransdutores presentes em determinados artrópodes, sendo que alguns têm função proprioreceptora e outros são receptores de vibração (Cabrini \& Andrade 2006).

Em registros de alguns naturalistas do século XIX e início do século XX pode-se observar a existência de textos e estudos que supõem a presença de um sistema auditivo nos crustáceos. Sobre este aspecto, Parker (1903) relatou que diversos artrópodes como os caranguejos, lagostas, insetos, miriápodes e outros possuem o sentido da "audição" ("hearing"). De modo similar, Farre (1843) descreveu os órgãos de "audição" ("hearing") de algumas espécies de crustáceos como as lagostas Astacus marinus (Fabricius, 1775), A. fluviatilis (Fabricius, 1775) e Palinurus sp. e uma espécie de caranguejo eremita, Pagurus streblomyx.

Posteriormente, Horch (1971) pesquisou o órgão responsável pela detecção de sons e vibrações em caranguejos do gênero Ocypode e constatou que outros membros da família Ocypodidae possuem "tímpanos" nas patas ambulatórias. Observou ainda, com base em seus experimentos, que as patas ambulatórias destes animais são os pontos mais sensíveis à percepção de estímulos sonoros, pois é nelas que está localizado o órgão miocordotonal.

Barth (1980) destacou que o caranguejo Carcinus maenas (Linnaeus, 1758) possui um órgão cordotonal na junção do dactilopodito com o propodito, capaz de perceber freqüências sonoras acima de $1 \mathrm{kHz}$. O autor ainda descreve uma estrutura situada no dactilopodito denominada "sensila campaniforme", a qual é sensível a estímulo sonoro. Esta sensila é capaz de responder as frequiências de sons com taxas de repetição de pulso de 12 a $24 \mathrm{~Hz}$ em Uca sp.e de 1 a $12 \mathrm{~Hz}$ em Ocypode spp. Em um experimento com caranguejos do gênero Ocypode, Horch (1974) demonstrou que o órgão miocordotonal de Barth, situado próximo ao músculo flexor acessório do mero, nas patas ambulatórias do animal, pode detectar frequiências sonoras acima de $1 \mathrm{kHz}$ e vibrações no substrato.

Em um estudo sobre os aspectos filogenéticos da audição, Balbani \& Montovani (2008) afirmam que dentre os crustáceos já estudados, a lagosta-da-Noruega (Nephrops norvegicus, Linnaeus, 1758) possui baixa sensibilidade auditiva, mas responde a estímulos sonoros na faixa de 20 a $180 \mathrm{~Hz}$. Os autores relatam ainda que os caranguejos dos gêneros Ocypode e $U c a$ produzem sons na faixa de $300 \mathrm{~Hz}$ a $3 \mathrm{kHz}$, e que esses sons são detectados pelos outros caranguejos através do órgão miocordotonal ou órgão de Barth, o qual permite a percepção de sons com freqüências acima de $300 \mathrm{~Hz}$.

Popper et al. (2001) em seu trabalho sobre detecção e comunicação acústica por crustáceos decápodes, relataram que mecanoreceptores, como pêlos sensoriais, podem responder a freqüências acima 
de $100 \mathrm{~Hz}$. Ainda segundo este autor, os caranguejos semi-terrestres Ocypode e Uca, não só produzem sons, como também respondem a sinais acústicos. Caranguejos do gênero $U c a$ produzem sons, com intensidade variando de 5 a $1500 \mathrm{~Hz}$, batendo seus dáctilos no substrato, para atrair as fêmeas durante o cortejo (Aicher et al. 1983). Uma analogia pode ser feita com os sons produzidos pelas catadoras entrevistadas nessa pesquisa, uma vez que elas percutem galhos retirados da parte superior do mangue sobre as "gaiteiras", existindo então a possibilidade desses estímulos sonoros serem detectados pelos aratus G. cruentata. Estudos experimentais sobre este aspecto bio-acústico podem, futuramente, testar esta hipótese, verificando a eventual capacidade de $G$. cruentata responder a esses estímulos sonoros.

A importância sócio-cultural da emissão de assobio para facilitar comunicação entre humanos tem sido registrada em diferentes sociedades (Meyer 2004). Contudo, estudos publicados sobre interações bio-acústicas entre humanos (coletores artesanais) e crustáceos, no processo de captura desses animais, são aparentemente inexistentes.

Não foi possível observar no discurso das informantes a preexistência de um conhecimento que lhes permitisse indicar que parte ou órgão específico no corpo do aratu é responsável pela capacidade auditiva desses animais. Ao serem questionadas sobre este aspecto, as entrevistadas apenas reafirmavam a existência da função auditiva nesses animais.

As catadoras entrevistadas exercem apenas este tipo de atividade pesqueira (coleta de aratu) e não costumam coletar regularmente outros animais estuarinos. É importante ressaltar que a pesca do aratu (Figura 2) é uma atividade predominantemente (mas não exclusivamente) feminina. Em alguns relatos das catadoras constatou-se a presença minoritária de alguns homens em seus grupos de pesca. Este resultado difere do de Fernandes (1996), apud Moura et al. (2003), que observou uma supremacia masculina na atividade de coleta deste e de outros crustáceos para o manguezal do rio Jaboatão, Pernambuco.

Cardoso (2002) em seu trabalho desenvolvido com catadoras de caranguejo do litoral norte da região amazônica fez uma ressalva quanto à desvalorização do trabalho feminino, especialmente no que diz a respeito à coleta de crustáceos. Segundo a autora, as próprias catadoras do litoral norte da região amazônica não reconhecem a importância do seu trabalho. O mesmo não parece ocorrer em relação

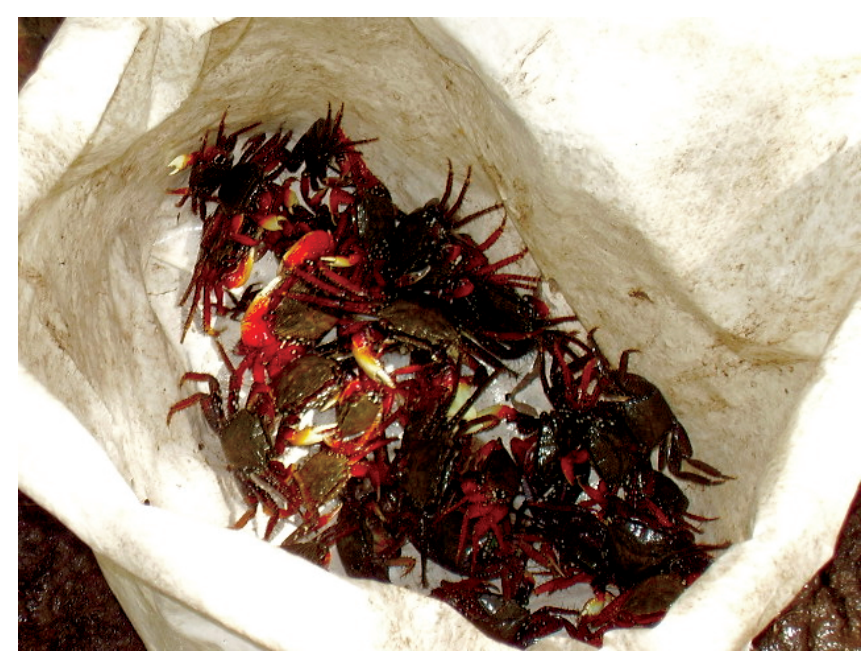

Figura 2. Aratus acondicionados em recipiente plástico, logo após serem capturados por uma informante.

Figure 2. Crabs in plastic bag, just after being captured by an informant. às catadoras de Barra de Sirinhaém. Estas, durante as entrevistas, demonstraram ter orgulho da atividade que exercem, e da experiência obtida durante anos de pesca, uma vez que a maioria das catadoras começou a praticar esta atividade ainda quando criança. Isto pode estar relacionado ao trabalho desenvolvido por instituições de defesa e promoção dos direitos dos pescadores na região. Neste sentido, uma informante declarou: "Ah, minha filha eu sou profissional, sou profissional disso", indicando assim que se trata de uma atividade cuja execução geralmente exige conhecimento prévio.

Segundo os relatos das entrevistadas há dois tipos de aratu: o "aratu-vermelho" e o "aratu-caboclo". Este último, segundo elas, é mais escuro que o primeiro e é utilizado por algumas para o preparo de remédio, os quais são utilizados pela população local para curar o que localmente se denomina "fraqueza". As etapas do tratamento com o caldo do aratu foram assim descritas por uma informante: "Bota um aratu no fogo, faz o pirão do caldo. Pra terminar tem que ser sete aratu. São sete dias. No primeiro dia um aratu, no segundo dois, até completar sete.”

O uso de crustáceos decápodes na fabricação de remédios tem sido apontado em alguns estudos. Guilherme Piso, médico acompanhante de Maurício de Nassau em Pernambuco no século XVII, relatou em sua obra "História natural e médica da Índia Ocidental", o uso do caranguejo "aratu" ou "aracu" (G. cruentata), moído e misturado com vinho, como antídoto contra todos os venenos (Almeida 2005). Outra aplicação terapêutica de G. cruentata foi descrita por Sassi et al. (2007), segundo o qual pescadores artesanais do rio Timbó, Pernambuco, utilizam o aratu para tratar doenças sexualmente transmissíveis. Silva et al. (2004) relataram que outro decápode, guajá, Calappa ocellata (Holthuis 1958), é vendido nos mercados públicos do Recife como produto zooterápico indicado popularmente para "cansaço" e "osteoporose".

Os dois "tipos" de aratu citados pelas entrevistadas e diferenciados por característica morfológica (cor), são da mesma espécie lineana ( $G$. cruentata), o que sugere que as catadoras tenham uma classificação taxonômica particular, diferente daquela que se aceita nos meios acadêmicos. Em um contexto semelhante, este sentido, Costa Neto (2007) relatou que pescadores de caranguejo-de-águadoce em Pedra Branca, Bahia, estabelecem uma diferenciação taxonômica baseada nas características morfológicas (cor) e características ecológicas (habitat).

O conhecimento das catadoras em relação a alguns aspectos da biologia do aratu está registrado na Tabela 1, onde se estabelece a cognição comparada (Marques 1995).

Os dados da Tabela 1 mostram que, em alguns aspectos, o conhecimento das catadoras entrevistadas é compatível com o conhecimento científico correlato. Estas informações podem ser úteis em programas de conservação e educação ambiental, uma vez que indicam perspectivas de diálogo entre os integrantes do meio técnico-científico e as pessoas que manejam cotidianamente os recursos naturais, muitas destas sem instrução formal.

Sobre a diferenciação sexual nos crustáceos braquiúros, Souto \& Marques (2006) em um estudo com pescadores de siris em Acupe, Bahia, observaram que juntamente com os caranguejos, os siris machos e fêmeas facilmente diferenciados pelos pescadores, com base na forma do abdome, o qual é localmente denominado "imbigo" e "tampo". Outro critério utilizado pelas entrevistadas em Barrra de Sirinhaém para fazer a diferenciação sexual do aratu é a proximidade entre o dedo móvel e o dedo fixo da quela do animal. Neste sentido, uma das informantes comentou que "quando a pata de agarrar (quela) tá mais ligada na ponta, é fêmea; quando tiver menos ligada é macho".

A ecologia trófica do aratu, conforme descrita pelas entrevistadas está ilustrada (Figura 3) em um modelo adaptado de Souto (2004), 
Tabela 1. Comparação entre informações fornecidas por catadoras entrevistadas e citações da literatura sobre aspectos biológicos do aratu G. cruentata.

Table 1. Comparison between information given by local crab gatherers and those found in scientific literature on the biology of G. cruentata.

\begin{tabular}{|c|c|}
\hline Informações das catadoras & Informações da literatura \\
\hline $\begin{array}{l}\text { "Os aratus ficam nos pé de pau [referindo-se à 'gaiteira' } \\
R . \text { mangle] quando a maré tá grande... Também ficam em } \\
\text { buracos enterrados na lama". }\end{array}$ & $\begin{array}{l}\text { G. cruentata é freqüentemente encontrado entre as raízes do mangue e mais } \\
\text { raramente nos ramos das árvores onde pode alcançar até } 2 \text { metros de altura; } \\
\text { também é encontrado nas tocas do caranguejo uçá (Ucides cordatus) (Calado } \\
\text { \& Souza 2002). } \\
\text { Este decápode habita os manguezais, mostrando ser um animal semi-arborícola ca- } \\
\text { paz de se deslocar rapidamente entre as raízes ou troncos de árvores, em sedimentos } \\
\text { médios ou pouco lamosos, e ativo durante a baixa-mar [...] (Botelho et al. 2004). }\end{array}$ \\
\hline "O aratu come xié, aratu pequeno, peixe, lula e aranhola." & $\begin{array}{l}\text { G. cruentata é considerado um animal onívoro, alimenta-se desde folhas de } \\
\text { mangue a cadáveres de crustáceos, incluindo-se os da própria espécie (Botelho, } \\
\text { 2004). } \\
\text { G.cruentata é um grande predador de manguezais (Leme 1995). }\end{array}$ \\
\hline $\begin{array}{l}\text { "Aratu, quando é na maré-de-quarto ele se descasca". } \\
\text { "Ele tira o casco duro e fica molezinho". } \\
\text { "Ele descasca pra crescer". }\end{array}$ & $\begin{array}{l}\text { Para crescer, todos os crustáceos, de tempos em tempos, desprendem o } \\
\text { exoesqueleto velho e é revestido com um novo, maior e mais flexível que o } \\
\text { precedente. Esse fenômeno é denominado muda ou ecdise (Igarashi 2007). }\end{array}$ \\
\hline $\begin{array}{l}\text { "O caranguejo (Ucides cordatus) escuta do mesmo jeito } \\
\text { do aratu, o guaiamum (Cardisoma guanhumi) é do mesmo } \\
\text { jeito. Siri (Callinectes spp.), aratu, caranguejo, guaiamum } \\
\text { tudo escuta". }\end{array}$ & $\begin{array}{l}\text { Decapod crustaceans have a variety of external and internal sensory receptors } \\
\text { that are potentially responsive to sound e vibration (Popper et al 2001). } \\
\text { Organs of sound reception include, in brachyurans, the chordotonal organs on } \\
\text { the hinges of walking legs (Encyclopædia Britannica 2008). }\end{array}$ \\
\hline "A fêmea, a barriga é larga. O macho, é estreita". & $\begin{array}{l}\text { Nos crustáceos braquiúros a forma do abdome permite a distinção do sexo, o } \\
\text { macho possui o abdome estreito, como formato de "T" invertido, enquanto a } \\
\text { fêmea possui quatro segmentos móveis com forma semicircular, quando madura, } \\
\text { e triangular quando imatura (Ribeiro-Costa \& Rocha 2002). }\end{array}$ \\
\hline $\begin{array}{l}\text { "A fêmea quando tá ovada fica cheia de ovinhos na ber- } \\
\text { guilha". }\end{array}$ & $\begin{array}{l}\text { A maioria dos crustáceos Malacostraca incuba seus ovos até o momento da } \\
\text { eclosão (Brusca \& Brusca 2007). } \\
\text { Nos caranguejos, o abdome em geral, firmemente flexionado, é abaixado para } \\
\text { permitir a incubação (Ruppert \& Barnes 1996). }\end{array}$ \\
\hline
\end{tabular}

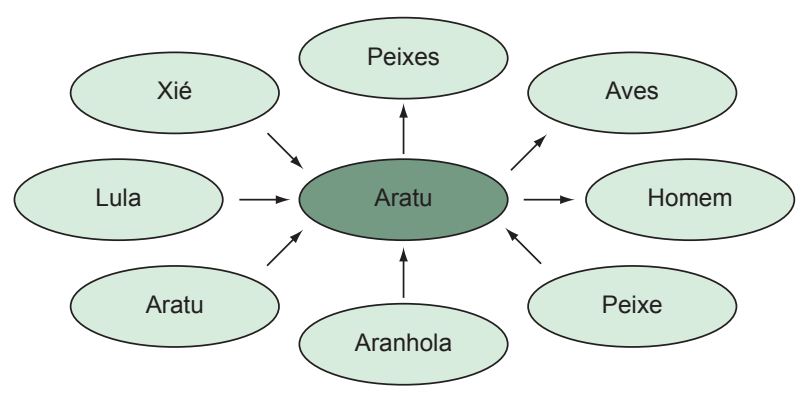

Figura 3. O aratu G. cruentata em um fragmento de rede trófica; modelo formado a partir das informações obtidas das entrevistadas.

Figure 3. The crab G. cruentata in a fragment of trophic chain; model built upon information given by local gatherers.

que insere $G$. cruentata em um fragmento de teia trófica. Através deste modelo pode-se observar a importância de G. cruentata na teia trófica de vários animais que vivem ou visitam os manguezais para se reproduzir e se alimentar, seja na qualidade de predador ou de presa.

Diferentes populações humanas utilizam uma terminologia própria para denominar diferentes partes do corpo dos animais, como registrou Souto (2004), que atribuiu a este tema o nome de "Topografia corporal". As catadoras atribuíram o nome "pata de morder" ao quelípodo do aratu, enquanto os pereópodos foram por elas denominados de "patas de apoio", sendo os do quinto par denominados individualmente de "pata midinha". Aquilo que, na literatura acadêmica, corresponde à carapaça, recebeu das informantes o nome

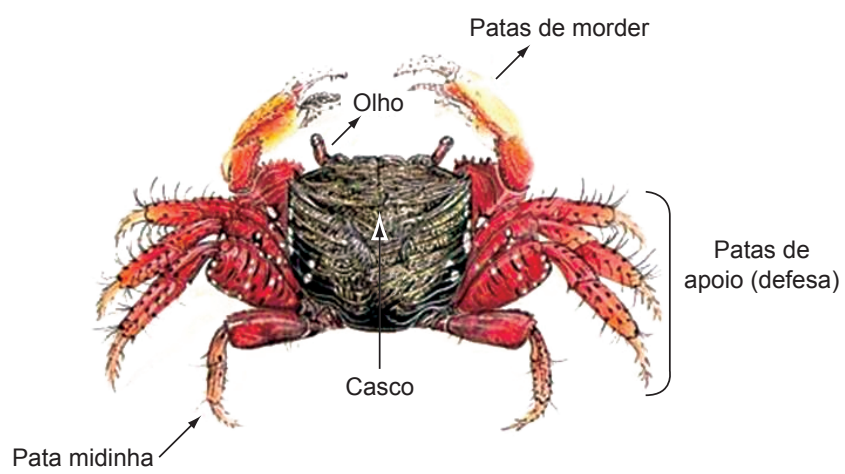

Figura 4. Topografia corporal do aratu G. cruentata, de acordo com informações fornecidas por catadoras em Barra de Sirinhaém (a partir de Figura adaptada de Rodrigues 1995).

Figure 4. Body topography of the crab G. cruentata, according to information given by local gatherers from Barra de Sirinhaém (after a Figure adapted from Rodrigues 1995).

de "casco" (Figura 4). Toda a região ventral do aratu, incluindo o que para Ruppert \& Barnes (1996) são os esternitos torácicos e o abdome, é denominado pelas catadoras de "barriga". Já a parte que corresponde ao abdome (Ruppert \& Barnes, 1996) é denominada pelas entrevistadas como "berguilha". Esta, segundo as mesmas, corresponde ao local onde as fêmeas incubam os ovos durante a reprodução, como se pode observar no discurso de uma das entrevistadas: "A fêmea fica com os ovos, quando a ova tá preta é porque tá choca. Ela começa a soltar os ovinhos quando a maré dá três lançamentos." 
As características morfológicas resultam importantes nos estudos de etnozoologia, porque é a partir da concepção geral do corpo do animal, incluindo a estrutura e a composição de suas partes, que uma rede cognitiva é pensada e construída sobre determinado animal que vive culturalmente compartilhado com os membros de uma população humana (Costa Neto 2007).

Durante as entrevistas, algumas catadoras afirmaram que o número de aratus nos manguezais de Barra de Sirinhaém vem diminuindo consideravelmente nos últimos anos, o que, segundo elas, implica no deslocamento das catadoras para outros locais onde a pesca deste animal pode ser mais lucrativa. Isto pode ser observado na fala de uma delas: "Eu vivo do mangue, a gente vive da pesca (...); já teve tempo de pegar $18 \mathrm{~kg}(. .$.$) ; hoje a gente ta pegando uns 2 \mathrm{~kg}$ (por dia).”

Costa Neto (2007) em um estudo etnoecológico com caranguejosde-água-doce Trichodactylus fluviatilis em Pedra Branca, Bahia, que a quantidade de T. fluviatilis estaria diminuindo devido especialmente aos impactos antrópicos, segundo o discurso dos catadores locais. Todavia, o autor destacou que seria preciso realizar estudos de ecologia populacional desses crustáceos para estimar a real situação da espécie na região.

Ainda sobre a provável redução populacional dos aratus, algumas catadoras em Barra de Sirinhaém citaram os impactos causados pelo turismo, pela pesca freqüente e desordenada no local, pelas criações de camarão, e pela utilização de pesticidas ("veneno"). Uma delas afirmou: "É muita gente que pesca aqui (...); aqui o usineiro botou o veneno nas cana e desceu pra o mangue. Caranguejo, siri, tudo morre, fica tudo espumando. O aratu só não morre tanto porquê vai pras gaiteiras”. (Entrevista, dados não publicados).

Algumas informantes associaram o fato de muitas pessoas pescarem no mesmo local e de forma desorganizada com a diminuição do recurso, bem como do tamanho do animal que é pescado. De modo semelhante, Moura et al. (2000) em um estudo realizado no litoral norte de Pernambuco sobre a captura do aratu, relataram a preocupação dos catadores locais com a diminuição na densidade destes animais. Ainda segundo os autores, o aumento do número de catadores, devido ao desemprego crescente, pode resultar, futuramente, em uma condição de sobre-pesca. Souto (2007) registrou que pescadores do distrito de Acupe, na Bahia, relataram que a quantidade de caranguejos no manguezal da região havia sido bem maior do que a que se observava na época da pesquisa. Ainda segundo o autor, todos os entrevistados afirmaram que a principal razão para a diminuição dos estoques de caranguejos ao longo do tempo teria sido o aumento no contingente de pessoas que passaram a se dedicar à atividade coletora.

A provável diminuição de G. cruentata, como também de outros crustáceos nos manguezais, tem sido citada em vários outros trabalhos. Alves \& Nishida (2003) relataram tendência semelhante em um trabalho com catadores de caranguejo-uçá (U. cordatus) no estuário do rio Mamanguape, onde os informantes atribuíram ao "veneno da cana", (referindo-se aos pesticidas lançados nas plantações de canade-açúcar) que, na época das chuvas eram carreados para o rio, a principal causa para a diminuição da quantidade de caranguejo-uçá no local. Neste sentido Braga (1986), relatou que a poluição das águas na zona estuarina de Barra de Sirinhaém, é gerada principalmente por despejos de resíduos das usinas de açúcar e destilarias de álcool existentes na bacia do rio Sirinhaém.

Outro fato que pode estar acarretando a suposta redução da população de aratus é a pesca predatória e não planejada. Botelho et al. (2004) supõe que a diminuição da população de caranguejo-uçá, Ucides cordatus, especialmente as altas mortalidades ocorridas na região Nordeste, tornou a captura do aratu ainda mais intensa. De acordo com dados do IBAMA/CEPENE (2000; 2007) entre os anos de 1999 e 2005 houve um aumento de aproximadamente $165 \%$ na produção de aratu (de 8,2 para 21,7 t), que pode ser resultado de uma prática de pesca não regulamentada.

Outro fator que deve ser ressaltado e que pode acelerar o processo de redução da população de G. cruentata, como também de outros animais que habitam ou passam pelo menos uma parte do seu ciclo de vida nos manguezais são as alterações ambientais que caracterizam o cenário atual. Neste sentido, Lacerda et al. (2006) afirmam que as mudanças climáticas, por exemplo, alteram drasticamente a extensão e características ambientais do ecossistema manguezal. O que resulta em uma influência direta ou indireta sobre a sobrevivência da fauna e flora nesse ecossistema. A maioria dos fenômenos naturais atua como tensores agudos afetando temporariamente os manguezais. Por outro lado, alguns eventos induzidos pelo homem, atuam como tensores crônicos perpetuando sua ação e seus impactos em longo prazo, podendo inclusive provocar destruição local dos manguezais (Varjabedian 1995).

A pesca artesanal do aratu constitui uma atividade fundamental para a subsistência das catadoras e também representa uma importante atividade econômica para a região. Observou-se entre as entrevistadas neste trabalho, a existência de um conjunto de conhecimentos sobre o ecossistema manguezal e sobre aspectos biológicos e ecológicos do aratu, como habitat, hábito, ecologia trófica, morfologia externa, comportamento, desenvolvimento e reprodução. Este conhecimento local, que habilita os informantes a exercerem suas práticas cotidianas, mostrou-se, em alguns casos, compatível com o conhecimento científico referente aos mesmos temas.

As informações obtidas nesta pesquisa podem contribuir para a conservação dos ambientes onde estes animais se encontram, fornecendo dados para elaboração de estratégias de manejo culturalmente apropriadas. Podem também ser úteis para expansão do conhecimento formal sobre G. cruentata, fornecendo novos dados e reforçando os existentes. Neste sentido, Nishida et al. (2006), enfatizaram que os dados levantados em pesquisas etnoecológicas podem promover um diálogo e cooperação entre os pescadores artesanais e os cientistas. Isto é ainda mais evidente quando se considera que ainda são poucos os estudos em relação à $G$. cruentata, crustáceo que possui grande importância ecológica e econômica no nordeste do Brasil.

\section{Agradecimentos}

A todas as catadoras de aratu que atuaram como informantes nesta pesquisa, pela atenção, receptividade e informações compartilhadas. A Raiana Lira Cabral pela contribuição na coleta de dados e à Renata Manzi de Souza, por ter proporcionado os contatos iniciais com as informantes.

\section{Referências Bibliográficas}

AICHER, B., MARKL, H., MASTERS, W.M. \& KIRSCHENLOHR, H.L. 1983. Vibration transmission through the walking legs of the fiddler crab, Uca pugilator (Brachyura, Ocypodidae) as measured by Laser Doppler Vibrometry. J. Comp. Physiol. A 150(4):483-491.

ALMEIDA, A.V. 2005. Prescrições zooterápicas indígenas brasileiras nas obras de Guilherme Piso (1611-1678). In Atualidades em Etnobiologia e Etnoecologia (A.G.C. ALVES, R.F.P. LUCENA, \& U.P. ALBUQUERQUE, orgs.). Nupeea; Sociedade Brasileira de Etnobiologia e Etnoecologia, Recife, p. 45-60. (v. 2).

ALVES, R.R.N. \& NISHIDA, A.K. 2002. A ecdise do caranguejo-uçá, Ucides cordatus (Crustacea, Decapoda, Brachyura) na visão dos caranguejeiros. Interciencia. 27(3):110 -117.

ALVES, R.R.N. \& NISHIDA, A.K. 2003. Aspectossocioeconômicos e percepção ambiental dos catadores de caranguejo-uçá Ucides cordatus cordatus (L. 1763) (Decapoda, Brachyura) do estuário do rio Mamanguape, nordeste do Brasil. Interciencia. 28(1):36-43. 
ANDRADE, C.T.S., MARQUES, J.G.W. \& ZAPPI, D.C. 2006. Utilização de cactáceas por sertanejos baianos: tipos conexivos para definir categorias utilitárias. Sitientibus Ser. Ci. Biol. 6(Número Especial Etnobiologia):6-12.

BALBANI, A.P.S., MONTOVANI, J.C. 2008. Aspectos filogenéticos da audição. Rev. Bras. Med. ORL 3(2):37-45. http://www.cibersaude. com.br/revistas.asp?fase $=$ r002\&id_edicao $=492$ (Último acesso em 25/11/2009)

BARTH, F.G. 1980. Campaniform sensilla: another vibration receptor in the crab leg. Naturwissenschaften. 67(4):201-202.

BRAGA, R.A.P. 1986. Caracterização preliminar da zona estuarina de Barra de Sirinhaém. Companhia Pernambucana do Meio Ambiente, Recife, 62 p. (Relatório de Pesquisa).

BOTELHO, R.O., ANDRADE, C.E.R. \& SANTOS, M.C.F. 2004. Estudo da População de Aratu-do-Mangue, Goniopsis cruentata (Latraille, 1803) (Crustacea, Decapoda, Grapsidae) no Estuário do Rio Camaragibe (Alagoas - Brasil). Bol. Tec. Cient. CEPENE 12(1):91-98.

BRUSCA, R.C. \& BRUSCA, G.J. 2007. Invertebrados. 2 ed. Guanabara Koogan, Rio de Janeiro.

BERNARD, H.R. 2005. Research methods in antropology: qualitative and quantitative approaches. 4 ed. Altamira, Lanham.

CABRINI, I. \& ANDRADE, C.F.S. 2006. Aspectos comportamentais de mosquitos em relação ao som: uma breve revisão. Unicamp, Campinas. http://www.ib.unicamp.br/profs/eco_aplicada/artigos_tecnicos.htm. (último acesso em 30/07/2008).

CALADO, T.C.S. \& SOUSA, E.C. 2002. Crustáceos do complexo EstuarinoLagunar Mundaú/Manguaba/Alagoas. FAPEAL, Maceió.

CARDOSO, D.M. 2002. Mulher, pesca e ambiente. In Anais do XXV Congresso Anual em Ciência da Comunicação. Intercom, Salvador. p. 1-12.

Companhia Pernambucana do Meio Ambiente - CPRH. 2003. Diagnóstico socioambiental do litoral sul de Pernambuco. CPRH, Recife.

COSTA-NETO, E.M. 2007. O caranguejo-de-água-doce, Trichodactylus fluviatilis (Latreille, 1828) (Crustacea, Decapoda, Trichodactylidae) na concepção dos moradores do povoado de Pedra Branca, Bahia, Brasil. Biotemas. 20(1):59-68.

COUTINHO, T.E. \& MOURA, G.F. 2008. Captura do caranguejo-aratu, Goniopsis cruentata (Crustacea, Decapoda, Grapsidae) na comunidade de São Lourenço. In Anais XXVII Congresso Brasileiro de Zoologia, Sociedade Brasileira de Zoologia / Universidade Federal do Paraná, Curitiba.

FARRE, A. 1843. On the Organ of Hearing in Crustacea. Philos. T. R. Soc. Lond. 133: 233-242.

HORCH, K. 1971. An organ for hearing and vibration sense in the ghost crab Ocypode. J. Comp. Physiol. A 73(1):1-21.

HORCH, K. 1974. Barth's myochordotonal organ as an acoustic sensor in the ghost crab, Ocypode. Experientia. 30(6):630-631.

Instituto Brasileiro do Meio Ambiente e dos Recursos Naturais Renováveis \& Centro de Pesquisa e Gestão de Recursos Pesqueiros do Litoral Nordeste. 2007. Boletim Estatístico da Pesca Marítima e Estuarina doNordeste do Brasil - 2005. Instituto Brasileiro do Meio Ambiente e dos Recursos Naturais Renováveis / Centro de Pesquisa e Gestão de Recursos Pesqueiros do Litoral Nordeste, Tamandaré. http://www. icmbio.gov.br/cepene/download.php?id_download=495 (último acesso em 25/11/2009)

Instituto Brasileiro do Meio Ambiente e dos Recursos Naturais Renováveis \& Centro de Pesquisa e Gestão de Recursos Pesqueiros do Litoral Nordeste. 2000. Boletim Estatístico da Pesca Marítima e Estuarina doNordeste do Brasil - 1999. Instituto Brasileiro do Meio Ambiente e dos Recursos Naturais Renováveis / Centro de Pesquisa e Gestão de Recursos Pesqueiros do Litoral Nordeste, Tamandaré. http://www. icmbio.gov.br/cepene/download.php?id_download=458 (último acesso em 25/11/2009).

IGARASHI, M.A. 2007. Sinopse da situação atual, perspectivas e condições de cultivo para lagostas Palinuridae. Cienc. Anim. Bras. 8(2):151-166.
LACERDA, L.D., MAIA, L.P., MONTEIRO, L.H.U., SOUZA, G.M., BEZERRA, L.J.C. \& MENEZES, M.O.T. 2006. Manguezais do Nordeste. Cienc. Hoje 39(229):24-29.

LEME, M.H.A. 1995. Ecologia Populacional de Aratus pisonii (H. MILNE EDWARDS, 1837) (Crustacea, Decapoda, Grapsidae) em uma área estuarina do litoral norte paulista. Dissertação de Mestrado, Universidade Estadual Paulista, São Paulo

LOVELL, J.M., FINDLAY, M.M., MOATE, R.M. \& YAN, H.Y. 2005. The hearing abilities of the prawn Palaemon serratus. Comp. Biochem. Physiol. 140(1):89-100.

Encyclopedia Britannica. 2008. Malascostracan. Encyclopedia Britannica, Chicago. http://www.britannica.com/EBchecked/topic/359445/ malacostracan (último acesso em 17/07/2008).

MARQUES, J.G.W. 1995. Pescando pescadores: uma etnoecologia abrangente no baixo São Francisco. NUPAUB; USP, São Paulo.

MELO, G.A.S. 1996. Manual de Identificação dos Brachyura (Caranguejos e Siris) do Brasileiro. Plêiade, São Paulo.

MEYER, J. 2004. Bioacoustics of human whistled languages: an alternative approach to the cognitive processes of language. An. Acad. Bras. Cienc. 76(2):405-412.

MOURA, F.B.P. \& MARQUES, J.G.W. 2007. Conhecimento de pescadores tradicionais sobre a dinâmica espaço-temporal de recursos naturais na Chapada Diamantina, Bahia. Biota Neotrop. 7 (3):119-126.

MOURA, N.F.O., COELHO-FILHO, P.A. \& COELHO, P.A. 2000. Captura de Goniopsis cruentata Latreille (1803) em um manguezal do litoral norte de Pernambuco - Brasil (Crustacea, Brachyura, Grapsidae). In Anais do Mangrove 2000. Universidade Federal Rural de Pernambuco, Recife. (CD-ROM)

MOURA, N.F.O., COELHO, P.A. \& SOUZA, R.F. 2003. A pesca artesanal do aratu, Goniopsis cruentata (Latreille, 1803) (Crustacea, Brachyura, Grapsidae) no Litoral Norte de Pernambuco - Brasil. Bol. Tec. Cient. CEPENE 11(1):109-115.

MOURA, N.F.O. \& COELHO, P.A. 2004. Maturidade sexual fisiológica em Goniopsis cruentata (Latreille) (Crustacea, Brachyura, Grapsidae) no Estuário do Paripe, Pernambuco, Brasil. Rev. Bras. Zool. 21(4):1011-1015.

NISHIDA, A. 2005. Etnoecologia de Manguezais. In Atualidades em etnobiologia e etnoecologia (A.G.C. Alves, R.F.P. Lucena \& U.P. Albuquerque, orgs.). Nupeea; Sociedade Brasileira de Etnobiologia e Etnoecologia, Recife, p. 184-194. (v. 2).

NISHIDA, A.K., NORDI, N. \& ALVES, R.R.N. 2006. Molluscs production associated to lunar-tide cycle: a case study in Paraíba State under ethnoecology viewpoint. J. Ethnobiol. Ethnomed. 2(28):1- 6.

OLMOS, F. \& SILVA, R.S. 2003. Guará: ambiente, flora e fauna dos manguezais de Santos-Cubatão. Empresa das Artes, São Paulo.

PARKER, G.H. 1903. The sense of hearing in fishes. Am. Nat. 37(435):185-204.

POPPER, A.N., SALMON, M. \& HORCK, K.W. 2001. Accoustic detection and communication by decapods crustaceans. J. Comp. Physiol. A 187(2):83-89.

POSEY, D.A. 1986. Etnobiologia: teoria e prática. In Suma etnoecológica brasileira. (B. Ribeiro, ed.). Vozes, Petrópolis, p. 15-25.

REBELO, F.C. \& MEDEIROS, T.C.C. 1988. Cartilha do Mangue. Universidae Federal do Maranhão, São Luís.

RIBEIRO-COSTA, C.S. \& ROCHA, R.M. 2002. Invertebrados: manual de aulas práticas. Holos, Ribeirão Preto.

RODRIGUES, S.A. 1995. O manguezal e sua fauna. Centro de Biologia Marinha, Universidade de São Paulo, São Sebastião. http://www.usp.br/ cbm/index.php/artigos-acesso-livre/76-o-manguezal-e-a-sua-fauna.html (último acesso em 24/08/2007).

RUPPERT, E.E. \& BARNES, R.D. 1996. Zoologia dos invertebrados. Roca, São Paulo.

SANTOS, M.C.F. \& BOTELHO, E.R.O. 2002. Estudos biológicos do aratu, Goniopsis cruentata (Latreille, 1803) (Crustacea: Decapoda:Grapsidae) 
no Estuário do Rio Uma, Município de São José da Coroa Grande (Pernambuco - Brasil). Bol. Tec. Cient. CEPENE 10(1):171-186.

SANTOS, G.M.T., ALVES, A.A. \& MENDONÇA, F.A.S. 2007. Morfologia de Estruturas Sensoriais em Pernas e Antenas de Agelaia pallipes (Olivier), Polybia paulista (Ihering) e Mischocyttarus cassununga (Ihering) (Hymenoptera: Vespidae). Neotrop. Entomol. 36(6): 868-873.

SASSI, R., CABRAL, A.L. \& COSTA, C.F. 2007. Pescadores artesanais do estuário do rio Timbó, Pernambuco, Brasil: cultura, sobrevivência e imaginário. Sitientibus. 7(1):86-97.

SILVA, M.L.V., ALVES, A.G.C. \& ALMEIDA, A.V. 2004. A zooterapia no Recife (Pernambuco): uma articulação entre as práticas e a história. Biotemas. 17(1):95-116.

SOUTO, F.J.B. 2004. A ciência que veio da lama: uma abordagem etnoecolóica abrangente das relações ser humano/manguezal na comunidade pesqueira de Acupe, Santo Amaro, Bahia. Tese de Doutorado, Universidade Federal de São Carlos, São Carlos.
SOUTO, F.J.B. \& MARQUES, J.G.W. 2006. "O siri labuta muito!”: uma abordagem etnoecológica abragente da pesca de uma conjunto de crustáceos no manguezal de Acupe, Santo Amaro, Bahia, Brasil. Sitientibus. 6(Número Especial - Etnobiologia):106-109.

SOUTO, F.J.B. 2007. Uma abordagem etnoecológica da pesca do caranguejo, Ucides cordatus, Linnaeus, 1763 (Decapoda: Brachyura), no manguezal do distrito de Acupe (Santo Amaro - BA). Biotemas. 20(1):69-80.

SPRADLEY, J.P. 1979. The ethnographic interview. Harcourt Brace Jovanovich, Fort Worth.

VARJABEDIAN, R. 1995. Impactos sobre os manguezais. In Manguezal: ecossistema entre a Terra e o mar. (Y. Schaeffer-Novelli, ed.). Instituto Oceanográfico, São Paulo.

Recebido em 08/03/09 Versão reformulada recebida em 04/08/09 Publicado em 08/10/09 